\title{
COLABORAÇÃO INTERNACIONAL ENTRE PROGRAMAS DE PÓS GRADUAÇÃO STRICTU SENSU
}

Elizabeth Bernardinoํㅡㄹ Clémence Dallaire², Maria Ribeiro Lacerda ${ }^{3}$

\begin{abstract}
RESUMO: O presente trabalho pretende relatar a experiência de colaboração entre professores de programas de pós-graduação strictusensu em Enfermagem que acontece entre a Universidade Federal do Paraná e a Universidade Laval no Canadá. Esta colaboração iniciou-se ao final de 2008 e as estratégias incluem a participação em bancas de qualificação e defesa, oportunidades de apresentação e participação em congressos internacionais financiados pela Coordenação de Aperfeiçoamento de Pessoal de Nível Superior, Fundação Araucária e Universidade Federal do Paraná, co-orientação de estudantes e oferta de disciplinas à distância. Elementos técnicos e facilitadores permitiram contornar as distâncias geográficas e culturais e fazer avançar a parceria. Os desafios são numerosos e se relacionam ao custeio das ações de integração, domínio de língua estrangeira, dificuldade em conciliar abordagens e objetos de pesquisa. Os benefícios se relacionam à discussão e análise da prática profissional em enfermagem sob novas abordagens em diferentes contextos. PALAVRAS-CHAVE: Cooperação internacional; Educação de pós-graduação em enfermagem; Docentes de enfermagem.

\section{INTERNATIONAL COLLABORATION BETWEEN POST-GRADUATE PROGRAMS STRICTU SENSU}

ABSTRACT: This work intends to relate the experience of collaboration - starting toward the end of 2008 - between professors of the Nursing post-graduate programs stricto sensu of the Federal University of Parana and Laval University in Canada. Strategies include the participation in examining panels for proposal defense, opportunities to present at, and participate in, international congresses financed by the Coordination for the Perfection of Higher Education Personnel, the Araucaria Foundation, and the Federal University of Parana, co-orientation of students and the offering of distance learning courses. Technical and facilitating elements permitted those involved to overcome geographical distances and cultural differences and take the partnership forward. The challenges are numerous and have to do with the bearing of the cost of integrative actions, sufficient fluency in the foreign language, and difficulty in conciliating approaches and research topics. The benefits are related to the discussion and analysis of professional practice in Nursing under new approaches in different contexts.

KEYWORDS: International cooperation; Post-graduate education in nursing; Nursing teachers.

\section{COLABORACIÓN INTERNACIONAL ENTRE PROGRAMAS DE POSGRADO STRICTU SENSU}

RESUMEN: Este trabajo tiene el propósito de relatar la experiencia de colaboración entre profesores de programas de posgrado strictu-sensu en Enfermería que ocurre entre la Universidad Federal de Paraná y la Universidad Laval en Canadá. Esa colaboración empezó al fin de 2008 y las estrategias incluyen la participación en mesas de calificación y defensa, oportunidades de presentación y participación en congresos internacionales financiados por la Coordinación de Perfeccionamiento de Personal de Nivel Superior, Fundação Araucária y Universidad Federal de Paraná, co-orientación de estudiantes y oferta de disciplinas a distancia. Elementos técnicos y facilitadores permitieron acortar las distancias geográficas y culturales, así como hacer avanzar la sociedad entre las instituciones. Los desafíos son numerosos y se relacionan al coste de las acciones de integración, dominio de lengua extranjera, dificultad en conciliar abordajes y objetos de investigación. Los benefícios se relacionan a la discusión y análisis de la práctica profesional en enfermería bajo nuevas abordajes en diferentes contextos. PALABRAS-CLAVE: Cooperación internacional; Educación de posgrado en enfermería; Docentes de enfermería.

${ }^{1}$ Enfermeira. Doutora em Enfermagem. Professora do Curso de Graduação e Programa de Pós-Graduação em Enfermagem da Universidade Federal do Paraná - UFPR. Professora Associada da Université Laval, Canadá.

${ }^{2}$ Enfermeira. Doutora em Enfermagem. Vice-reitora de Estudos Superiores e de Pesquisa da Faculdade de Enfermagem da Universidade Laval. Responsável da Faculdade junto ao Centro FERASI (Centre de Expertise em Sciences Infirmières).

${ }^{3}$ Enfermeira. Doutora em Enfermagem. Professora do Curso de Graduação e Programa de Pós-Graduação em Enfermagem da UFPR. Líder do Núcleo de Estudos, Pesquisa e Extensão em Cuidado Humano em Enfermagem - NEPECHE.

Autor correspondente:

Elizabeth Bernardino

Universidade Federal do Paraná

Rua Francisco Querino de Lima, 199 - 82015-360 - Curitiba-PR-Brasil

E-mail: elizaber@ufpr.br
Recebido: 18/02/2011

Aprovado: 01/07/2011 


\section{INTRODUÇÃO}

A cooperação internacional com objetivo de auxiliar na formação dos profissionais não é nova no Brasil. Um exemplo histórico foi a cooperação internacional entre a Fundação Rockefeller e os governos brasileiros, que deu a tônica, num certo período da história sanitária no país, caracterizada pela ênfase no ensino da higiene e na formação de profissionais de saúde pública, desde as primeiras décadas do século $20^{(1)}$. O que se observa é que as reformas na educação são consequências das influências de organismos internacionais e de políticas de órgãos governamentais e estão vinculadas tanto às novas relações entre Estado e universidades como à construção de políticas educacionais regionais e de internacionalização das instituições ${ }^{(2)}$.

Atualmente, há um debate sobre o processo de integração regional das universidades da Europa e também das Américas do Norte e Central, como consequência das políticas governamentais implementadas na construção dos blocos da União Europeia (UE) e do Tratado de Livre Comércio de América do Norte (Nafta), orientadas, em primeiro lugar, para a inserção dos diferentes países no mundo econômico globalizado ${ }^{(2)}$.

Ao longo do século XX, as necessidades do caráter internacionalista da produção do conhecimento científico se vincularam às necessidades e pressões dos Estados, das sociedades e do mercado, no contexto do desenvolvimento nacional. As políticas nacionais mudaram o foco de ensino e pesquisa nas universidades públicas, deixando de ter como principal preocupação indagações científicas e necessidades sociais mais amplas e passando a privilegiar os interesses comerciais e estratégicos ${ }^{(3-4)}$.

$\mathrm{O}$ "capitalismo acadêmico"(5) define a maneira pela qual as universidades e seus pesquisadores reagem frente à tendência de vincular as políticas de ensino superior às necessidades da política econômica, com os pesquisadores e administradores universitários induzidos a participar de ambientes competitivos para captação de recursos públicos e privados, direcionando seus projetos segundo os interesses do mercado.

Diante dos objetivos comuns a serem alcançados no mundo globalizado, as universidades passam a exercer a cooperação internacional de maneira mais pragmática, o que enseja tanto benefícios quanto prejuízos. Os benefícios incluem: compartilhamento de alguns custos; acesso a experiências, tecnologias e instalações; criação ou estreitamento de boas relações; mútua-influência; e desenvolvimento de liderança. Os prejuízos são: perda de liberdade de ação, com a criação de dependências; incremento da complexidade gerencial; riscos políticos se a cooperação falhar, além da transferência indesejada de tecnologia ${ }^{(6)}$.

As políticas de internacionalização da universidade encontram-se principalmente no campo de cooperação internacional de diferentes instituições governamentais de desenvolvimento de recursos humanos de ensino superior e de desenvolvimento científico e tecnológico como a Coordenação de Aperfeiçoamento de Pessoal de Nível Superior (CAPES) e o Conselho Nacional de Desenvolvimento Cientifico e Tecnológico $(\mathrm{CNPq})^{(2)}$. Tais políticas incluem formação na graduação, pós-graduação, pesquisas conjuntas, formação de recursos humanos locais e programas de formação interinstitucional ${ }^{(2)}$.

Tais políticas universitárias dependem da definição dos objetivos, da forma como ela será feita e de medidas ou estratégias para a efetivação das mesmas ${ }^{(7)}$. No caso específico da pós-graduação, a internacionalização requer medidas que ultrapassem o âmbito do ensino, envolvendo também pesquisas e, para tanto, deve-se prever o uso de idiomas estrangeiros como ferramenta indispensável para este fim ${ }^{(7)}$.

Como o Brasil, outros países, incluindo o Canadá, possuem estratégias de internacionalização de suas universidades, financiadas por agências públicas ou da iniciativa privada. A despeito de se compreender as contradições, os conflitos e os interesses do mercado na internacionalização das universidades, esta é uma realidade e faz parte da avaliação dos programas de pós-graduação. Ao nos depararmos com essa meta em nossa universidade, sentimo-nos na obrigação de desenvolver, conscientemente, estratégias que potencializem os benefícios dessa forma de cooperação.

A princípio, todos os professores que vivenciam uma experiência em universidades estrangeiras durante estágios de doutoramento ou pós-doutoral podem, em tese, dar continuidade aos projetos de colaboração; mas, nem sempre isto acontece, visto que consumar e sustentar um acordo até o final de um projeto é uma tarefa árdua, pois todos os parceiros tentam maximizar seus próprios interesses, suas agendas particulares ${ }^{(6)}$. Neste caso, a convergência de interesses e a afinidade conceitual e intelectual entre alguns professores foram catalizadores para a colaboração aqui enfocada.

É neste contexto, que o presente trabalho pretende relatar a experiência de colaboração entre professores de programas de pós-graduação strictu-sensu em Enfermagem que acontece entre a Universidade Federal do Paraná-UFPR e a Universidade Laval no Canadá-ULa- 
val. Com o apoio da CAPES, da Fundação Araucária e da UFPR, os resultados foram apresentados na Segunda Conferência Anual Internacional para Enfermeiros Educadores em Washington DC, Estados Unidos, promovido pela Global Alliance for Leadership in Nursing Education and Science-GANES em dezembro de 2010.

\section{A COOPERAÇÃO ENTRE OS PROGRAMAS DE PÓS-GRADUAÇÃO EM ENFERMAGEM DA UFPR E DA ULAVAL}

As duas universidades possuem políticas de cooperação internacional, o que possibilitou a assinatura de um acordo. Na UFPR, a Assessoria de Relações Internacionais é responsável pela profissionalização e institucionalização das ações de cooperação para a internacionalização da universidade. Sua missão é propor e executar uma política que consolide a abertura da UFPR para maior inserção internacional, enfocando a mobilidade acadêmica (docente e discente) e técnica, promovendo a internacionalização do ensino superior, da pesquisa e da extensão, a fim de formar profissionais capazes de competir no mercado de trabalho globalizado ${ }^{(8)}$.

A ULaval possui um escritório internacional cuja missão é desenvolver estratégias e assegurar serviços necessários à operacionalização das políticas institucionais em matéria de internacionalização da formação e cooperação internacionais, com recursos próprios, provinciais ou federais ${ }^{(9)}$.

As duas universidades encerram objetivos, com relação à cooperação internacional, coerentes e convergentes com as propostas dos programas de pósgraduação. Curiosamente, ambos possuem histórias semelhantes. O Programa de Pós-Graduação em Enfermagem da UFPR, o PPGENF, surgiu de uma construção coletiva dos professores do Departamento de Enfermagem, inicialmente, pela participação no Curso de Mestrado em Enfermagem da Universidade Federal de Santa Catarina, sendo efetivada duas ofertas, por meio da Rede de Pós-Graduação em Enfermagem da Região Sul-REPENSUL; e outra por convênio interinstitucional com o apoio da Fundação Araucária, na década de 90 do século passado.

De acordo com as normas vigentes (Portaria Ministerial n. 2264, de 19 de dezembro de 1997), o Curso de Mestrado em Enfermagem da UFPR foi aprovado em 2002. O programa oferece, atualmente, Mestrado Acadêmico e Doutorado em Enfermagem, este criado em 2010, e Programa de Mestrado Profissional em Enfermagem, aprovado recentemente. O PPGENF conta com 60 alunos, sendo 42 mestrandos e 18 doutorandos.

O Programa de Mestrado em Enfermagem da ULaval existe há 20 anos e oferece três modalidades diferentes: mestrado com estágio e ensaio; mestrado com dissertação e mestrado prático para enfermeiras especializadas. A cada ano, aproximadamente 30 enfermeiras iniciam o mestrado nas duas primeiras modalidades e 20 na segunda. Os programas de mestrado em enfermagem objetivam, antes de tudo, desenvolver uma expertise clínica de nível de prática avançada, pela aquisição de conhecimentos e habilidades necessárias a essa prática. Todos os 24 professores do Curso de Enfermagem podem orientar os estudantes no programa de mestrado.

Quanto ao Programa de Doutorado, ele foi oficialmente iniciado em abril de 2010 e conta, atualmente, com 13 estudantes. Este programa prepara líderes científicos que contribuirão de forma dinâmica para gerar os conhecimentos necessários ao desenvolvimento e à evolução da Enfermagem enquanto ciência, e se tornarão professores de carreira, pesquisadores autônomos ou consultores para o governo ou organizações nacionais e internacionais.

O início desta parceria se deu em 2008, pelo contato anterior de uma professora do programa que realizou seu estágio de doutorado na universidade canadense, financiado pela Capes. Após o término do doutorado, a parceria se estabeleceu com várias atividades; a aproximação entre os programas se deu com inserções das professoras canadenses e brasileiras em aulas de ambos os programas, por videoconferência.

Atualmente, há uma professora do programa brasileiro como professora convidada na Faculdade de Enfermagem da ULaval e duas professoras canadenses no PPGENF UFPR.

Concomitantemente, pesquisas sobre as funções do enfermeiro em vários contextos de trabalho no Brasil foram iniciadas, a partir do referencial de Clémence Dallaire $^{(10-11)}$ : a primeira delas, uma monografia de conclusão de curso de graduação, em Unidade de Terapia Intensiva; uma segunda, em Unidade de Transplante de Medula Óssea e concluída em 2011; a terceira, como uma dissertação de Mestrado que tem a professora canadense como co-orientadora.

Outro ponto de intercâmbio foi a participação de uma professora do PPGENF UFPR no colóquio franco-canadense "Prendre soins: savoirs, pratiques et perspectives", que foi planejado e efetivado no Centro Internacional de Cérisy-la-Salle, na França e apresentou um trabalho cujo título foi "Composantes universelles et culturelles des soins au Brésil", uma 
pesquisa realizada por três professores dos referidos programas.

Em abril de 2011 foi ofertada uma disciplina para o Programa de Doutorado da UFPR, planejada e executada pelas professores canadenses e viabilizada por meio de vídeoconferência, intitulada "Seminários Avançados: Perspectivas de Análise das Organizações de Saúde".

Os resultados das avaliações dos alunos, na participação das atividades bilaterais, mostram que eles se sentem beneficiados pelo acesso a outra realidade e outras abordagens teóricas, contribuindo para refletir criticamente sobre as dimensões da prática profissional. Um ponto importante foi mostrar aos alunos a necessidade de dominar outra língua e, assim, ter acesso às pesquisas, trabalhos e banco de dados estrangeiros, que permitirá ampliar as discussões e pensar em um conhecimento globalizado.

\section{CONSIDERAÇÕES FINAIS}

Consideramos que as parcerias internacionais envolvem muito trabalho do tipo cooperativo, tanto no sentido de aproximar conceitos e transpor as barreiras da língua, como para solucionar problemas técnicos, o que demanda um empenho preciso e considerável. Os resultados compensam o esforço, a formação de grupos consolida as alianças e fortalece a compreensão dos avanços e dos problemas comuns à profissão.

Salientamos que o acesso a experiências e tecnologias, o estreitamento de boas relações e o desenvolvimento de lideranças são os principais benefícios relatados pelos professores implicados nas atividades desta cooperação internacional e compensam a burocracia para a obtenção de recursos financeiros, e os esforços para a colução de questões técnicas e ideológicas, geralmente presentes nesses processos. Neste sentido, este relato também aponta a necessidade de uma reflexão sobre a política de internacionalização, suas fragilidades e potencialidades, e qual seria o papel docente neste processo de globalização, até para repensar as bases para outras parcerias.

\section{REFERÊNCIAS}

1. Santos LAC, Faria LR. A cooperação internacional e a enfermagem de saúde pública no Rio de Janeiro e São Paulo. Revista Horizontes. 2004;22(2):123-50.

2. Krawczyk NR. As políticas de internacionalização das universidades no Brasil: o caso da regionalização no
Mercosul. J Polít Educ. 2008;(40):41-52.

3. Contento J, Slaughter S, Leslie LL. Academic capitalism: politics, policies and the enterpreneurial University. [Internet] In: Education review. Baltimore: John Hopkins University Press; [acesso em 20 mar 2011] Disponível: http://edrev.asu.edu/reviews/rev14.htm

4. Krawczyk NR, Sandoval AS. As políticas de regionalização das universidades do Mercosul: um estudo das mudanças institucionais [projeto de pesquisa]. CNPq; 2007.

5. Slaughter S, Leslie L. Expanding and elaborating the concept of academic capitalism. Organization. 2001;8(2):154-61.

6. Silva DH. A cooperação internacional em ciência e tecnologia: oportunidades e riscos. Rev Bras Polít Int. 2007;50(1):5-28.

7. Marrara T, Rodrigues JA. Medidas de internacionalização e o uso de idiomas estrangeiro. RBPG: Rev Bras PosGrad. 2009;6(11):121-43.

8. Universidade Federal do Paraná [Internet]. Curitiba: Universidade Federal do Paraná; [acesso em 07 ago 2010]. Disponível: http://www.internacional.ufpr.br/

9. Université Laval. Bureau Internacional [Internet]. Canadá: Université Laval; [acesso em 07 ago 2010]. Disponível: http://www.bi.ulaval.ca/mission.html

10. Dallaire C. Les grandes fonctions de la pratique infirmiére. In: Goulet OE, Dallaire C, organizadores. Soins infirmers vers des nouvelles perspectives. Boucherville: Gaëtan Morin Editeur; 1999.

11. Dallaire C, Dallaire M. Le savoir infirmier dans les fonctions infirmières. In: Dallaire $\mathrm{C}$, organisateur. Le savoir infirmier: Au coeur de la discipline et de la profession. Montréal: Gaëtan Morin; 2008.

Cogitare Enferm. 2011 Out/Dez; 16(4):749-52 